\title{
What is the Impact of Utility Demand Charges on an Alternating Current Level 2 Elective Vehicle Supply Equipment Host?
}

Idaho National Laboratory

June 2015

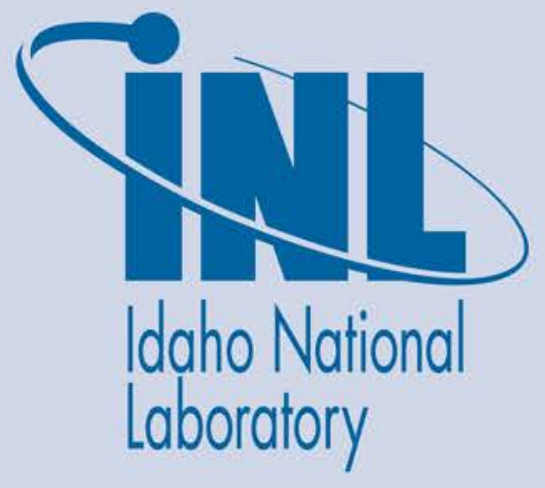

The INL is a U.S. Department of Energy National Laboratory operated by Battelle Energy Alliance 


\section{What is the Impact of Utility Demand Charges on an Alternating Current Level 2 Elective Vehicle Supply Equipment Host?}

Idaho National Laboratory

June 2015

Idaho National Laboratory

Idaho Falls, Idaho 83415

http://www.inl.gov 


\section{What is the Impact of Utility Demand Charges on an Alternating Current Level 2 Elective Vehicle Supply Equipment Host?}

June 2015

\section{Key Conclusions}

- Some electric utilities in The EV Project market areas impose demand charges on the highest power delivered to a customer in a month.

- Simultaneously charging plug-in electric vehicles via multiple alternating current (AC) Level 2 (ACL2) electric vehicle supply equipment (EVSE) can create significant increases in power demand.

- These demand charges can have a significant impact on monthly electric utility costs, especially for small businesses.

- The increased charging rate allowed by many newer plug-in-electric vehicles (PEVs) will exacerbate this impact.

- A separately metered EVSE charging service may enable ACL2 charging site hosts to avoid most of these impacts.

\section{Introduction}

EVSE delivered by The EV Project included both residential and non-residential units. Approximately 4,000 non-residential ACL2 EVSE were installed in workplace environments, fleet applications, and publicly accessible locations near retail centers, parking lots, and similar locations. The Blink ACL2 utilized in The EV Project is capable of charging at up to $7.2 \mathrm{~kW}$, although most vehicles in The EV Project charged at about $3.7 \mathrm{~kW}$. This power can be a significant additional electrical load for the charging site host. This concern becomes greater when several EVSE are in operation on a site at the same time.

Many electric utilities include maximum power demand as part of their commercial rate structure. The demand charge incurred by a commercial customer is related to the peak power used during a monthly billing cycle. This is in contrast to the total energy usage, which is the more familiar utility charge seen for residential service. A demand charge is typically calculated based on the highest average power level over a 15-minute period during the monthly billing cycle and is not a cumulative-type charge.
One objective of The EV Project was to elucidate the motivations and hindrances to potential, non-residential EVSE, site hosts. The imposition of electric utility demand charges represents such a potential hindrance.

This subject was introduced in the paper titled, "DC Fast Charge - Demand Charge Reduction,", which specifically deals with direct current fast chargers. The concept remains relevant to ACL2 EVSE, especially when several EVSE are deployed at the same site, which occurred frequently in The EV Project. In fact, the average number of ACL2 EVSE per site was 2.58 , and it varied by market averaging 1.79 to 3.45 per site.

This paper identifies the impact of demand charges on non-residential ACL2 hosts in The EV Project.

\section{Background}

The EV Project recommended that all charging site hosts for fleet, workplace, or publicly accessible EVSE should contact their local electric utility for guidance in selecting the optimum arrangement for providing power to their EVSE. Essentially two options were available: (1) either the EVSE is powered from spare capacity within the existing service to the facility or (2) new service is added through a new electric meter. Selection of the best option would include consideration of the nature of the business, the desired location of the installed EVSE, existing facility power demand, capability of the existing service to accommodate new loads, local permitting requirements, and special rates that may be applied by the local utility.

Fleet and workplace hosts in The EV Project were responsible for the electrical power and energy costs required to operate EVSE as part of their business expenses. Publicly accessible EVSE hosts were compensated for all or part of the energy dispensed through revenue sharing of the EVSE access fees. Some of the hosts elected to provide the charging service at no cost to the PEV driver. In these cases, the host was responsible for all charging costs, including compensating Blink for their network services. Revenue from EVSE access fees was shared based on the length of time a PEV was connected to the EVSE and did not allow for any additional costs associated with utility demand charges.

Electric utilities provide rate schedules for commercial customers based on their history of energy and power demand. Appendix $A$ of this document provides rate schedules for an electric utility involved with The EV Project. Arizona Public Service Company (APS) provides service to most of the metropolitan Phoenix area and other parts of the state. It provides rate schedules for extra small commercial businesses (i.e., 0 to $20 \mathrm{~kW}$ in demand), small commercial (i.e., 21 to $100 \mathrm{~kW}$ ), medium commercial (i.e., 101 to $400 \mathrm{~kW}$ ), large commercial (i.e., $401 \mathrm{~kW}+$ ), and 
extra-large commercial (i.e., $3 \mathrm{MW}+$ ). The effects of EVSE charging are explored for the first three rate schedules in the following sections.

\section{Data Analyzed}

This paper utilizes typical host usage load profiles combined with actual ACL2 EVSE charge data collected by The EV Project to measure impact on demand charges. Using the APS rate schedules, the cost impact of each is identified. Three months of charge data were selected for analysis: June, July, and August 2013. These months were chosen because deployment of non-residential EVSE was essentially completed by this time interval; therefore, PEV drivers were well aware of the location of these EVSE. In addition, the fee structure for EVSE access had been in place for approximately 1 year and its effect on utilization was stable.

\section{Customer Load Profile Analysis}

\section{Extra Small Office Analysis}

The extra small office rate schedule does not impose demand charges. Its maximum limit on demand is $20 \mathrm{~kW}$. Addition of a PEV that is capable of charging at $6.7 \mathrm{~kW}$ would still allow over $13 \mathrm{~kW}$ of demand for normal business loads. This would allow this extra small business to continue typical summer loads (such as air conditioning) without impact. However, as the business grows or more PEV charging is installed, the $20-\mathrm{kW}$ limit may be exceeded and the next rate schedule would apply.

\section{Small Office Analysis}

OpenEI provides analyses on renewable energy and energy efficiency. It provides load profiles ${ }^{2}$ for various-sized businesses in each of the major regions of the United States. Those load profiles are used for further analysis in Phoenix.

The small office average load profile in the Phoenix area, as provided by OpenEl for June through August, is shown in Figure 1.

Should the office desire to add charging for a single PEV with the capability of charging at $6.7 \mathrm{~kW}$, the resulting load profile would be similar to that shown in Figure 2.

Peak demand is $6.7 \mathrm{~kW}$ higher during charging than the otherwise peak demand during this period, resulting in a total demand of $22.8 \mathrm{~kW}$.

This peak exceeds the 20-kW limit and would result in APS placing the customer in the next highest rate schedule:

E-32 S. It also results in a demand charge of $\$ 224 /$ month and subjects the company to demand charges as long as it remains on the new schedule. According to the APS rate schedule, this demand charge is added to the monthly statement in which it occurred, regardless of whether the EVSE ever charges again during the month.

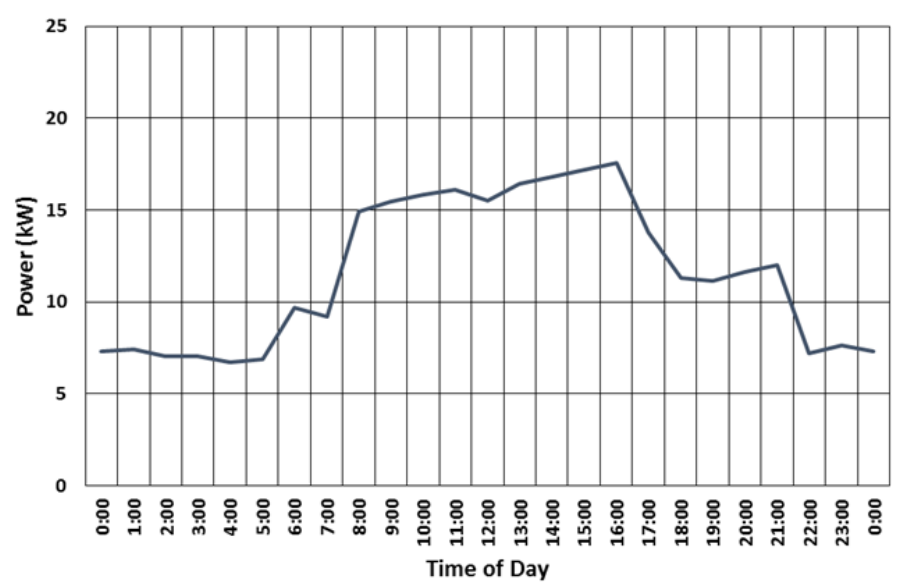

Figure 1. Phoenix small office profile.

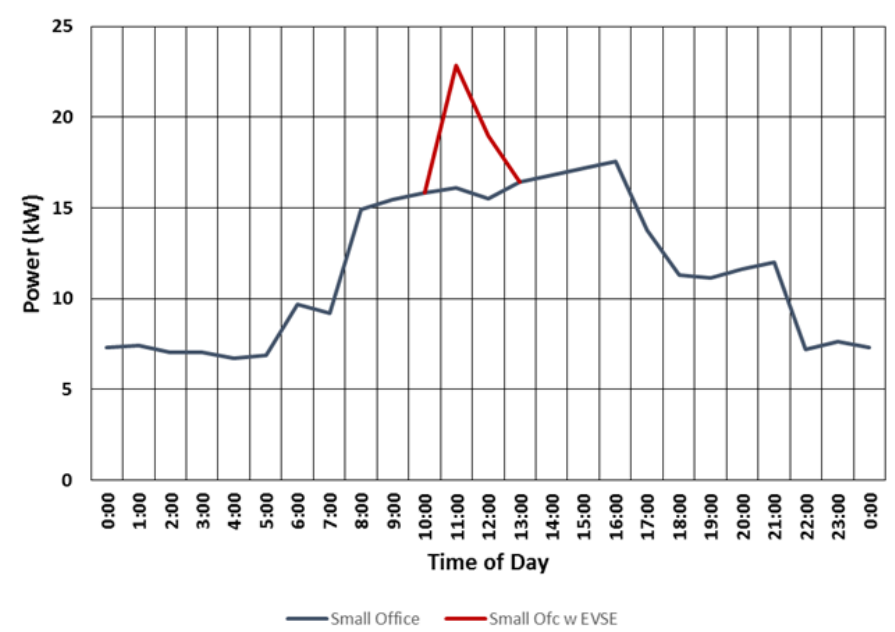

Figure 2. Phoenix small office with EVSE charging profile.

\section{Full-Service Restaurant Analysis}

The full-service restaurant average load profile in the Phoenix area, as provided by OpenEl for June through August, is shown as the blue line in Figure 3. On June 13, 2013, a site containing seven publicly accessible EVSE in the APS service territory experienced three of these EVSE charging simultaneously with a total demand of $9.9 \mathrm{~kW}$. The effect on the average profile from these three EVSE charging simultaneously is shown in Figure 3.

This customer would typically be assigned rate schedule E-32 S. Charging at the particular time observed resulted in a peak demand that was $4.7-\mathrm{kW}$ higher than the other peak of the day. This increases the monthly demand charge by \$46/month from a \$705/month demand charge without EVSE charging to a \$751/month with charging. Had the charging peak occurred simultaneously with the normal 
peak, the demand charge increase would have been $\$ 97 /$ month. While the host may be partially compensated by revenue sharing of the access fee, the increase in demand was not compensated by The EV Project. In this situation, the host's increase is only the amount of demand caused by the EVSE.

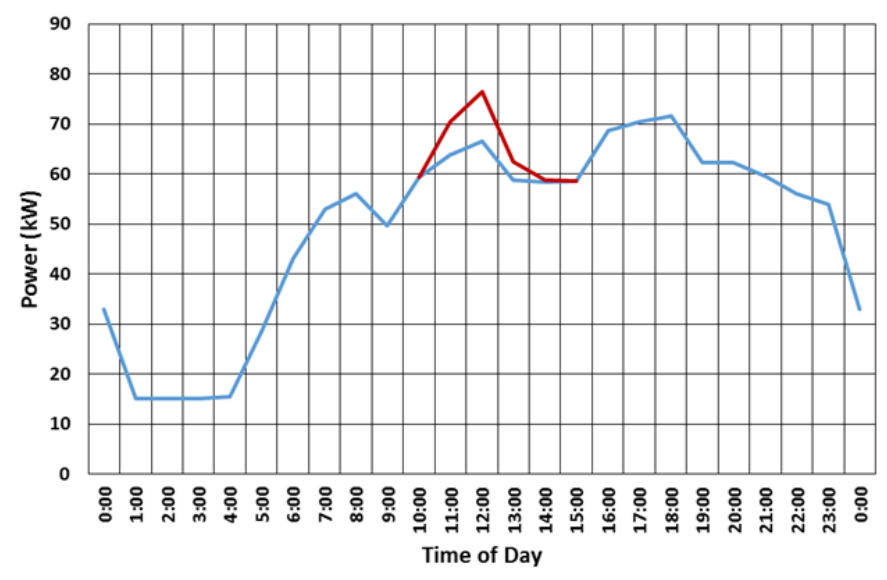

Figure 3. Phoenix full-service restaurant with EVSE profile.

\section{Supermarket Analysis}

The supermarket average load profile in the Phoenix area, as provided by OpenEl, for June through August is shown in Figure 4, along with the three EVSE charging events previously identified.

The supermarket would likely be on rate schedule E-32 M. Charging at the particular time observed resulted in a peak demand $2 \mathrm{~kW}$ higher than the other peak of the day. This increased the monthly demand charge by $\$ 10$ compared to the regular demand charge of $\$ 2,374$. Had the charging occurred simultaneously with the supermarket peak, the added monthly demand charge would be $\$ 53$.

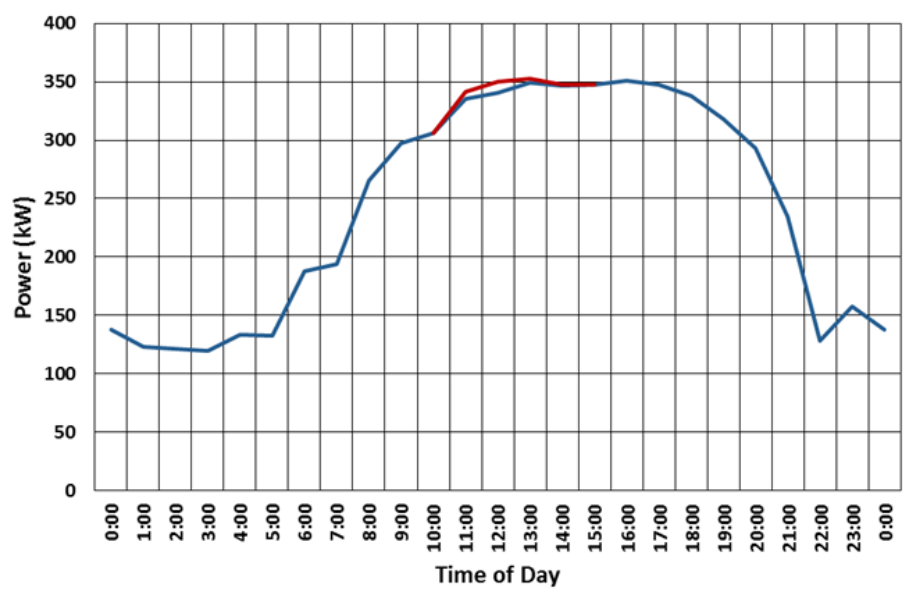

Figure 4. Phoenix supermarket with EVSE charging profile.

\section{Time-of-Use Rates}

Some electric utilities, such as Portland General Electric, offer commercial customers the option of applying time-ofuse (TOU) rates for PEV charging. This may require a separate electrical service, adding the costs associated with meter installation. TOU rates are provided by the electric utility to incentivize customers to charge PEVs on off-peak times. However, publicly accessible EVSE are typically available at all times of the day and are more likely to be utilized by the public during peak times. Thus, TOU rates are not likely to be helpful in reducing electricity costs for the restaurant or supermarket noted above. TOU rates may be beneficial for fleets or workplace environments, where the time when charging occurs can be controlled.

\section{Separately Metered Electric Vehicle Supply Equipment Service}

The above examples assume that EVSE charging is added to the existing electrical service provided to the facility. In most cases, prior consultation with the electric utility would identify that separate service is typically desirable. This separate service incurs the added expenses of miscellaneous fees and service charges for the new service but could prevent the added expense of demand charges. The three EVSE operating simultaneously in Phoenix could be assigned to the E-32 XS schedule and avoid all demand charges.

\section{Effects of Higher-Rate Charging}

The EVSE charge events noted above involve the original Leaf and Volt of The EV Project, with a maximum charging power demand from the grid limited by the vehicle to approximately $3.7 \mathrm{~kW}$. Newer models of the Leaf and many other PEVs entering the market have increased the charge capability of the vehicle to a power demand of $6.7 \mathrm{~kW}$ or greater. The Blink EVSE installed by The EV Project in non-residential locations is capable of delivering this increased power. Thus, the simultaneous operation of three EVSE could easily be over $20 \mathrm{~kW}$, rather than the $9.9 \mathrm{~kW}$ of that analyzed above.

\section{Observations}

Power required by the EVSE is a more significant impact to the electric utility's monthly statement for smaller commercial businesses than larger ones. Each electric utility defines small commercial businesses and their rate schedules based on its own needs and as regulated by the local Public Utility Commission or municipal rules. Some small business owners who have included EVSE charging as part of their existing supply may be surprised when the utility places them on a higher rate schedule as a result of 
PEV charging. Although it includes more upfront costs, separately metered service for the EVSE may allow the business owner and PEV charging host to avoid demand charges associated with ACL2 EVSE charging.

\section{About The EV Project}

The EV Project was the largest PEV infrastructure demonstration project in the world, equally funded by the United States Department of Energy (DOE) through the American Recovery and Reinvestment Act and private sector partners. The EV Project deployed over 12,000 AC Level 2 charging stations for residential and commercial use and over 100 dual-port direct current fast chargers in 17 U.S. regions. Approximately 8,300 Nissan LEAFs ${ }^{\mathrm{TM}}$, Chevrolet Volts, and Smart ForTwo Electric Drive vehicles were enrolled in the project.

Project participants gave written consent for EV Project researchers to collect and analyze data from their vehicles and/or charging units. Data collected from the vehicles and charging infrastructure represented almost 125 million miles of driving and 4 million charging events. The data collection phase of The EV Project ran from January 1 , 2011, through December 31, 2013. Idaho National Laboratory is responsible for analyzing the data and publishing summary reports, technical papers, and lessons learned on vehicle and charging unit use.

\section{Company Profile}

Idaho National Laboratory is one of DOE's 10 multi-program national laboratories. The laboratory performs work in each of DOE's strategic goal areas: energy, national security, science, and the environment. Idaho National Laboratory is the nation's leading center for nuclear energy research and development. Day-to-day management and operation of the laboratory is the responsibility of Battelle Energy Alliance.

For more information, visit avt.inl.gov/evproject.shtml and avt.inl.gov/chargepoint.shtml.

\section{References}

${ }^{1}$ http://avt.inl.gov/pdf/EVProj/DCFastChargeDemandChargeReductionV1.0.pdf [accessed March 14, 2015].

${ }^{2}$ OpenEl load profiles, http://en.openei.org/datasets/files/961/pub/.

${ }^{3}$ APS Business Electric Rate Schedules, http://www.aps.com/en/ourcompany/ratesregulationsresour ces/serviceplaninformation/Pages/business-sheets.aspx.

${ }^{4}$ Portland General Electric Rate Schedules, https://www.portlandgeneral.com/our company/corporate i nfo/regulatory documents/tariff/rate schedules.aspx. 


\section{Appendix A}

\section{Electric Utility Overview}

\section{Arizona Public Service ${ }^{3}$}

APS rate schedules are provided in reference 3 . While all rate schedules contain basic service charges and fees, the charges of interest are for energy and power demand.

Monthly maximum demand will be based on the highest average $\mathrm{kW}$ supplied during the 15-minute period during either the on-peak or off-peak hours of the billing period, as determined from readings of the company's meter.

APS has no special distinction related to businesses charging PEVs.

APS also offers TOU options related to these rates. However, public charging of PEVs are generally not limited to off-peak times and such may not be a benefit. They are omitted here for clarity.

Table A-1 shows the basic differences between rate schedules for energy usage and demand.

A-1. APS rate schedules for commercial customers.

\begin{tabular}{|c|c|c|c|}
\hline Schedule & Max kW & Energy & Demand \\
\hline$E-32 X S$ & 20 & $\begin{array}{c}\$ 0.13537 / \mathrm{kwh} \\
\text { first } 5,000 \mathrm{kWh} \text {, } \\
\text { plus } \$ 0.07427 \\
\text { for additional } \\
\mathrm{kWh}\end{array}$ & NA \\
\hline E-32 S & 100 & $\begin{array}{c}\$ 0.10337 \text { per } \\
\text { kWh for first } \\
200 \mathrm{kWh} \text {, plus } \\
\$ 0.06257 \mathrm{for} \\
\text { additional kWh }\end{array}$ & $\begin{array}{l}\$ 9.828 \text { per } \mathrm{kW} \\
\text { for the first } \\
100 \mathrm{~kW} \text {, plus } \\
\$ 5.214 \text { for all } \\
\text { additional } \mathrm{kW}\end{array}$ \\
\hline E-32 M & 400 & $\begin{array}{c}\$ 0.09884 \text { per } \\
\text { kWh for the first } \\
200 \mathrm{kWh} \text {, plus } \\
\$ 0.06091 \text { per } \\
\text { kWh for all } \\
\text { additional kWh }\end{array}$ & $\begin{array}{c}\$ 10.235 \text { for } \\
\text { the first } \\
100 \mathrm{~kW} \text {, plus } \\
\$ 5.385 \text { per kW } \\
\text { for all } \\
\text { additional kW }\end{array}$ \\
\hline
\end{tabular}

